\title{
Juxtaposition of the atrial appendages in a patient with a simple ventricular septal defect
}

Julie Cleuziou, MD, PhD, MBA, ${ }^{a}$ Jakob Kemmer, MD, ${ }^{b}$ Ursula Sauer, MD, ${ }^{c}$ and Milka Pringsheim, MD, Munich, Germany

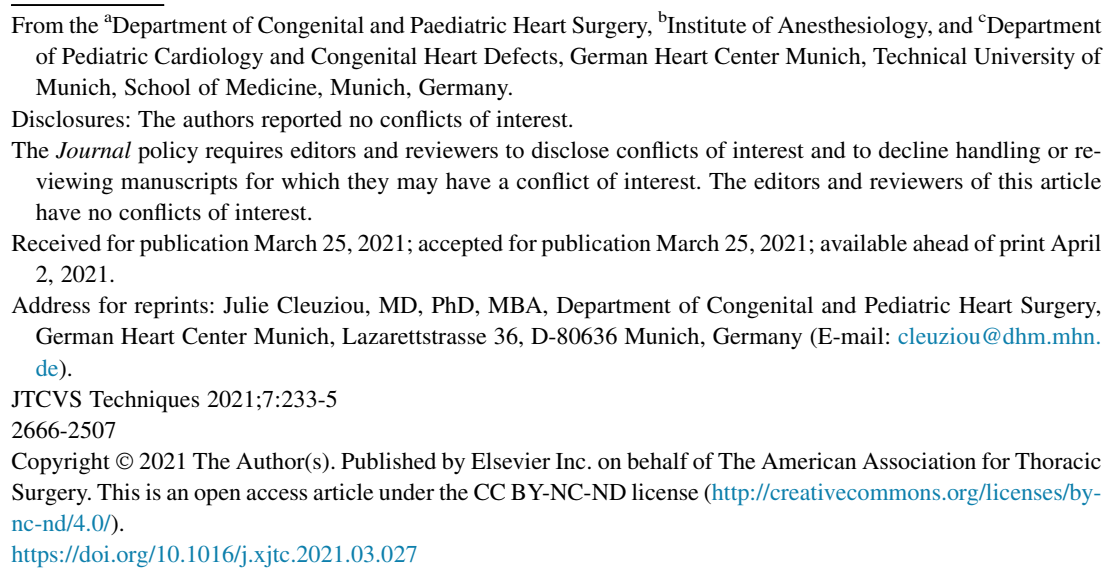

Video clip is available online.

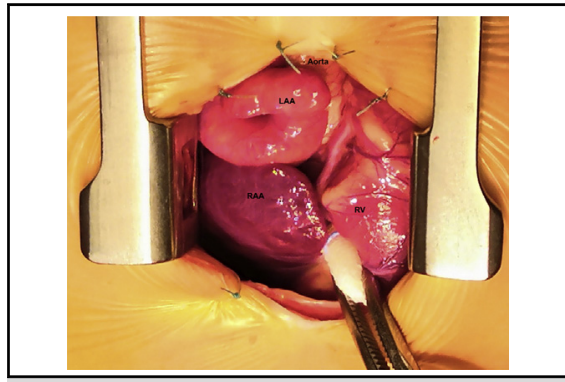

Intraoperative view showing right juxtaposition of the left atrial appendage (LAA).

CENTRAL MESSAGE

Right juxtaposition of the left atrial appendage is a rare finding in a simple congenital heart defect and has no implication for its treatment.

See Commentaries on pages 236 and 238 .

\section{CASE DESCRIPTION}

An 11-week-old female was diagnosed with a perimembranous ventricular septal defect (VSD) after failure to thrive. She was pale and exhibited slight subcostal retractions. The 2-dimensional (2D) echocardiographic findings were levocardia, situs solitus of the atria, concordant atrioventricular and ventriculoarterial connections, normally connected systemic and pulmonary veins, mildly enlarged left heart structures, and no outflow tract obstructions. Color flow Doppler revealed a large $(10 \mathrm{~mm})$ perimembranous VSD with left-to-right shunt without a pressure gradient between the ventricles, and no other shunt between the atria and vessels.

Surgery was performed through a median sternotomy. On opening the pericardium, a juxtaposition of the left atrial appendage to the right of the great arteries was discovered (Figure 1; Video 1). Its origin from the left atrium was normal, and its course was typical behind the great arteries toward the right of the aorta, located medial and superior to the right atrial appendage. Notably, the juxtaposed left atrial appendage was enlarged and bright red.

Extracorporeal bypass was established through aortic and bicaval cannulation. After cardioplegic cardiac arrest, the right atrium was opened. The VSD was closed with a polytetrafluoroethylene patch and a running polypropylene suture through a transatrial approach. The operation was uneventful, as was the postoperative course. The patient was extubated 6 hours after surgery and discharged to home on postoperative day 7 .

In retrospect, analysis of the preoperative 2D echocardiographic images revealed an abnormal structure in the parasternal long-axis view (Figure 2, A). Furthermore, in the tilted 5-chamber view, a long structure behind the aorta was found, raising the suspicion of juxtaposed atria (Figure 2, B).

The infant's parents consented to publish this case.

\section{DISCUSSION}

There are 2 remarkable findings in this case: the position on the right side of the left atrial appendage and the missing association with a complex heart defect except for a VSD. The juxtaposition did not influence the treatment of the child, who underwent an uneventful VSD closure in a standardized manner.

Juxtaposition of the atrial appendages (JAA) is described in the literature as a rare condition, usually 


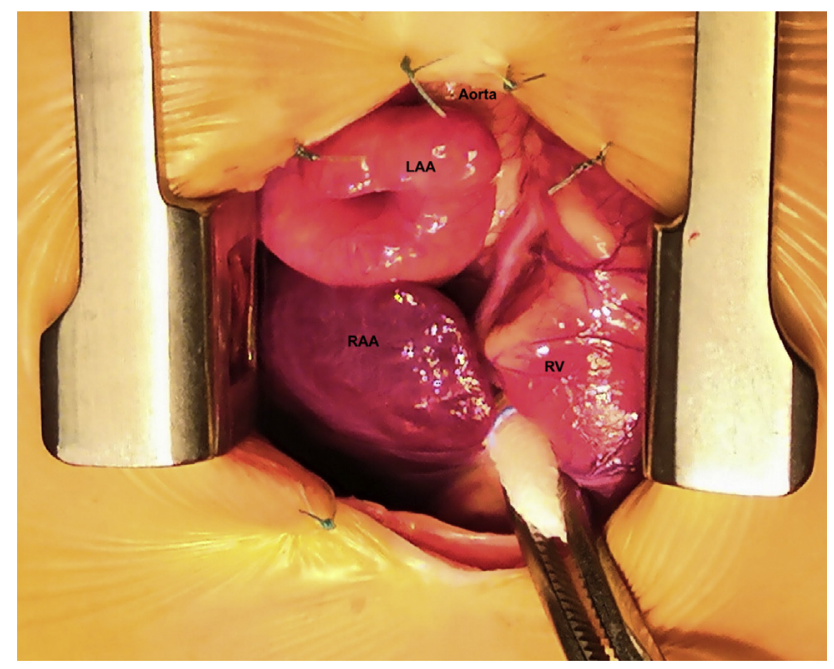

FIGURE 1. Intraoperative view showing both atrial appendages on the right side of the aorta. The left atrial appendage ( $L A A)$ lies superior to the right atrial appendage $(R A A)$. The patient's head is at the top of the picture. $R V$, Right ventricle.

associated with complex cardiac malformations. ${ }^{1}$ We found a right JAA (RJAA) with both atrial appendages lying on the right side of the great arteries and the left atrial appendage lying superiorly. The morphology and the origin of the atrium were normal in both appendages. In autopsy series, the incidence of RJAA is as low as $12 \%$, compared with $88 \%$ for a left JAA (LJAA). Moreover, RJAA is commonly associated with complex lesions of the left side of the heart, such as hypoplastic left ventricle or obstruction of the left ventricular outflow tract. ${ }^{2}$ The benign occurrence of JAA without associated cardiovascular anomalies has no hemodynamical impairment and is remarkably rare, with only a few cases reported to date.

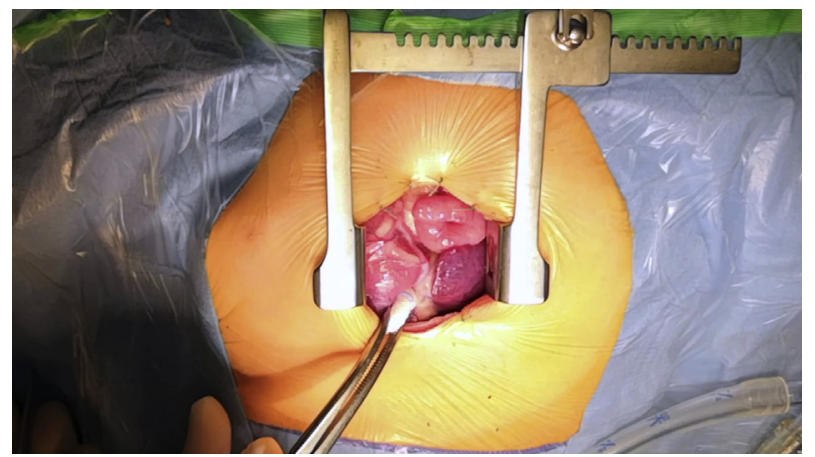

VIDEO 1. Video showing the juxtaposed left atrium (bright red) superior to the right atrium (dark red) on the right side of the aorta. The patient's head is on the top of the picture. Video available at: https://www.jtcvs. org/article/S2666-2507(21)00277-7/fulltext.

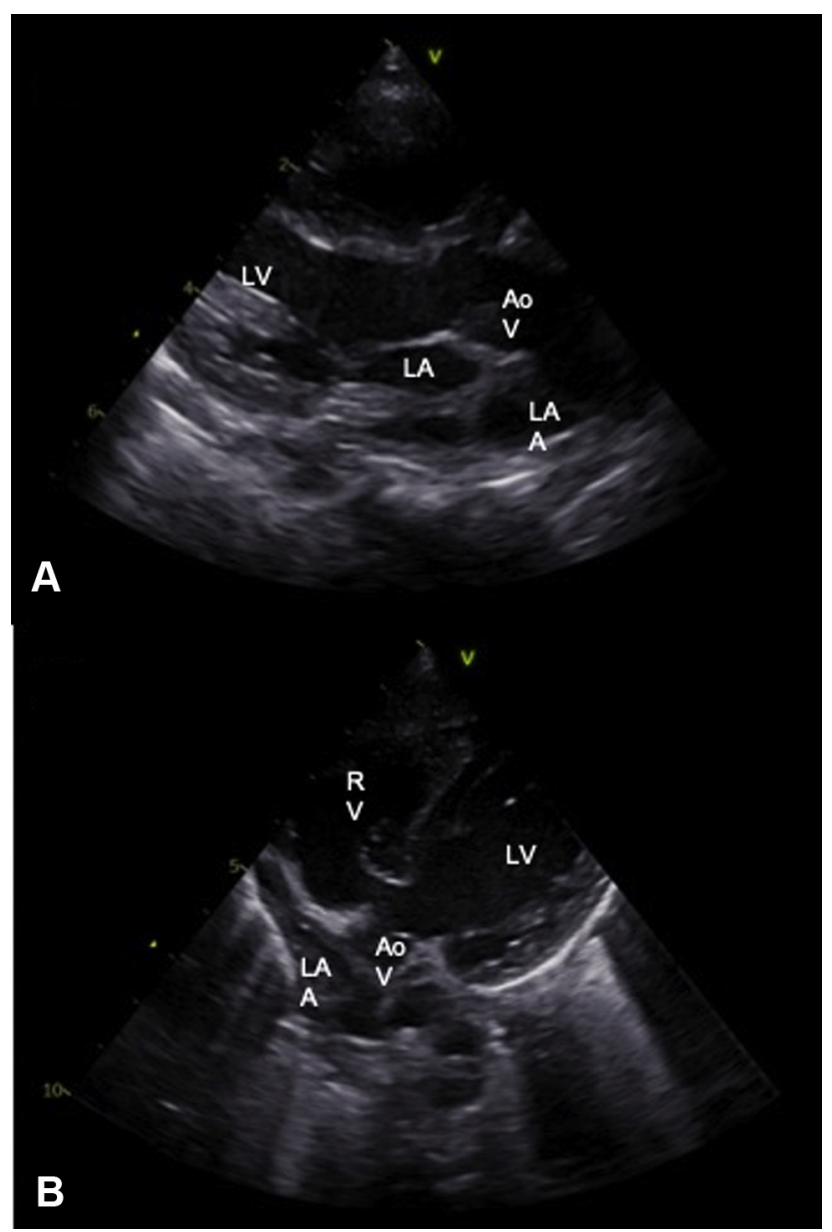

FIGURE 2. Preoperative transthoracic echocardiography. A, Parasternal long-axis view showing the left atrial appendage $(L A A)$ cranial to the left atrium $(L A)$. B, Tilted 5-chamber view showing the LAA behind the aorta. $L V$, Left ventricle; $A o V$, aortic valve.

Becker and colleagues ${ }^{3}$ reported on a stillborn child with an atrial septal defect and a bicuspid pulmonary valve, associated with RJAA. A recent report described an adult with a bicuspid aortic valve and RJAA who required surgery for severe aortic stenosis. ${ }^{4}$ As in our case, the diagnosis of RJAA was found unexpectedly after thoracotomy and the preoperative $2 \mathrm{D}$ echocardiogram was reanalyzed in retrospect.

Diagnosis of JAA is challenging. Although the distinct morphology and position of the atrial appendages are determinants of the atrial situs, and JAA is a reliable marker of association with complex congenital heart disease (CHD), evaluation of the atrial appendages is generally not part of the standardized 2D echocardiographic evaluation. In view of the higher incidence of JAA in complex CHD, it is probably sufficient to include the echocardiographic analysis of the morphology and position of both atrial appendages only in patients with complex CHD. 


\section{References}

1. Van Praagh S, O'Sullivan J, Brili S, Van Praagh R. Juxtaposition of the morphologically left atrial appendage in solitus and inversus atria: a study of 18 postmortem cases. Am Heart J. 1996;132(2 Pt 1):391-402.

2. Frescura C, Thiene G. Juxtaposition of the atrial appendages. Cardiovasc Pathol. 2012;21:169-79.

3. Becker AE, Becker MJ. Juxtaposition of atrial appendages associated with normally oriented ventricles and great arteries. Circulation. 1970;XLI: 685-8.

4. Boutayeb A, Kenassi F, Bensouda A, Marmade L. Isolated right juxtaposition of the atrial appendages in adult with bicuspid aortic valve stenosis. World J Pediatr Congenit Heart Surg. 2017;8:635-6. 